PUB-753

\title{
Lawrence Berkeley Laboratory Ergonomics Committee FY 94 Annual Report
}

November 1994

Lawrence Berkeley Laboratory

University of California

Berkeley, CA 94720

Supported by the U.S. Department of Energy under Contract DE-AC03-76SF00098.

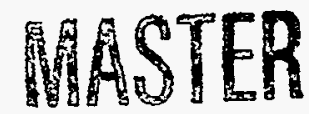

DISTRIBUTION OF THIS DOCUMENT IS UNLIMITED

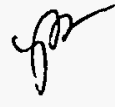




\section{DISCLAIMER}

Portions of this document may be illegible in electronic image products. Images are produced from the best available original document. 


\section{DISCLAIMER}

This report was prepared as an account of work sponsored by an agency of the United States Government. Neither the United States Government nor any agency thereof, nor any of their employees, make any warranty, express or implied, or assumes any legal liability or responsibility for the accuracy, completeness, or usefulness of any information, apparatus, product, or process disclosed, or represents that its use would not infringe privately owned rights. Reference herein to any specific commercial product, process, or service by trade name, trademark, manufacturer, or otherwise does not necessarily constitute or imply its endorsement, recommendation, or favoring by the United States Government or any agency thereof. The views and opinions of authors expressed herein do not necessarily state or reflect those of the United States Government or any agency thereof. 


\section{EXECUTIVE SUMMARY}

In January 1994, the LBL Ergonomics Committee was established by the Environment, Health and Safety (EH\&S) Division Director. Members from an ad-hoc committee, the "Ergonomics Council", which had existed for a number of years, were folded into the committee in addition to other labwide representatives. The LBL Ergonomics Committee was established because there has been a substantial increase in the number of Cumulative Trauma Disorders (CTDs) ${ }^{1}$ experienced by employees at LBL and trends nationwide (i.e., VDT injuries, back injuries). The purpose of the Committee is to focus on strategies to reduce the occurrence of CTDs in the workplace. The LBL Ergonomics Committee has participated in numerous activities during its first year to enhance the awareness of ergonomics at LBL, and to minimize employee exposure to ergonomic hazards that can lead to CTDs. This report highlights the Committee's accomplishments for fiscal year 1994 (FY 94), and goals for FY 95.

During FY 94, the Committee made marked progress in several areas:

- Policy Development Developed an LBL Ergonomics Policy that was approved by the Director's Action Committee (DAC) in April 1994 (see Appendix A).

- Data Analysis

Reviewed risk management data and LBL workplace accident analysis reports to assess trends at $\mathrm{LBL}$ on the types of employee injuries: The data show that the second most common reportable accident type at LBL is repetitive strain injuries. The data also show that the total cost for workers' compensation claims increased $64 \%$ from FY 92 to $F Y$ 93, but then decreased $64 \%$ from FY 93 to FY 94 (see Appendix B) ${ }^{2}$. The cost for repetitive strain injuries (RSIs) followed the same pattern. The increase in RSI claims and cost for FY 93 can be attributed to employees becoming aware that RSls can result in serious injuries, and hence an increase in reporting. This is a common result. The

Note 1: CTDs are also referred to as repetitive strain injuries (RSIs).

Note 2: The figures for FY 92 are an estimate. 
percentage of total claims attributed to RSIs has begun to decrease (33\% for FY $93,20 \%$ for FY 94). In addition, data show that the total number of VDT claims has decreased since 1992. The reduction in RSI costs and VDT claims indicate that Committee activities are having a positive impact at LBL.

(The University of California workers' compensation statistics system-wide indicate a consistent increase in the number of CTD claims and costs for FY 89 to FY 93. The number of CTD claims increased from approximately 150 in FY 89 to over 475 in FY 94. The cost increased from approximately $\$ 1.5$ million in FY 89 to over $\$ 3.0$ million in FY 94. This information is provided to indicate that the cost associated with CTDs claims can be expensive.) ${ }^{3}$

\section{- Legislative Review}

Reviewed current laws, regulations and standards as they relate to occupational ergonomic issues: Committee members provided input on a new chapter of LBL's Health and Safety Manual (PUB 3000), Chapter 17, titled "Ergonomics". The latest revision of PUB 3000 was released in June 1994. Committee members also provided input to the Department of Energy (DOE) on two ergonomic proposals; DOE's proposed Ergonomic Order, and the National Institute of Occupational Safety and Health / Occupational Safety and Health Administration (NIOSH/OSHA) Ergonomic Standard (draft). In addition, several Committee members attended a public hearing in San Francisco to provide input on Cal-OSHA's proposed Ergonomic Standard.

- Employee Training

Developed goals regarding the education of affected groups at LBL: The LBL Ergonomics Committee continuously monitors the types of employee injuries that occur. This provides a basis for determining what kind of ergonomic classes are needed. EH\&S Training developed a new Back Injury Prevention Training Program. The Committee interacted with EH\&S Training to develop the Back Injury Prevention course. Eighteen classes were taught and 234 employees were trained.

Note 3: The figures prior to FY 93 are an estimate. CTDs were not recorded as a separate category at that time. 
- Employee Awareness

Sponsored and supported activities to enhance employee awareness of ergonomics (see Appendix C): The Committee sponsored Ergonomics Awareness Week in February 1994, and supported Ergonomics on Parade in September 1994. These two events attracted a total of over 400 employees. Also, Committee members attended safety committee meetings for the following divisions and discussed ergonomics; Administration Division, Chemical Sciences Division, Energy \& Environment Division, Engineering Division, Environment, Health \& Safety Division, Information \& Computing Sciences Division, Materials Sciences Division, Nuclear Science Division, Physics Division.

- Research and Development

Followed new developments in workstation furniture and equipment, such as ergonomic chairs, computer workstation design, and alternative keyboards: An ergonomically correct computer workstation is set up at the Office Ergonomics Lab, located in trailer 7B (see Appendix D). Also, ergonomic furniture can be borrowed to "try out" and determine if it's suitable for an employee's needs prior to purchasing.

The LBL Ergonomics Committee launched proactive programs and activities in FY 94. The challenge ahead in FY 95 is to continue using a systems and proactive approach to enhance the awareness of workplace ergonomics, and integrate ergonomic improvements for a safe and healthful workplace. Specific goals for FY 95 are to seek funding to upgrade the Office Ergonomics Lab (see Appendix E), find a permanent location for the Office Ergonomics Lab, and sponsor more activities to enhance employee awareness of ergonomics. 


\section{CONTENTS}

Executive Summary .............................................................................................

First Year in Review (FY 94) .................................................................1

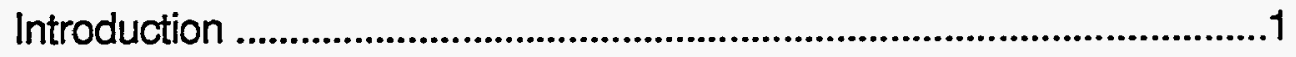

Committee Membership ...........................................................................

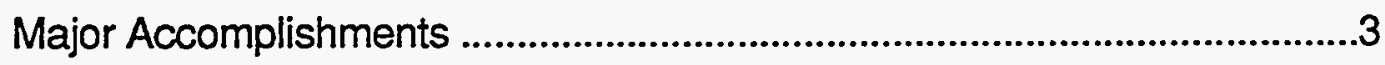

LBL Ergonomics Policy .............................................................................

Health and Safety Manual (PUB 3000) .............................................3

Ergonomic Inspection Assessment ...............................................4

Ergonomics Legislation ......................................................................4

Ergonomics Training ……....................................................................

Ergonomics Awareness Week .............................................................5

Ergonomics On Parade ...........................................................................

Other Accomplishments .............................................................................6

LBL Office Ergonomics Lab .........................................................6

LBL Ergonomic Furniture Policy ....................................................6

LBL Chair Loaner Program .................................................................6

Planning For the Future ................................................................................

Opportunities for Improvement ..................................................... 
Ergonomic Legislation ................................................................................

Ergonomic Furniture and Accessories ...................................................

APPENDIX A: LBL Ergonomics Policy

APPENDIX B: LBL Ergonomic Statistics

APPENDIX C: Ergonomics Awareness Week Information

APPENDIX D: LBL Office Ergonomics Lab Information

APPENDIX E: Request for Committee Funding 


\section{FIRST YEAR IN REVIEW}

\section{Introduction}

The LBL Ergonomics Committee had its beginnings in 1985, when representatives of the Environment, Health and Safety (EH\&S) Department, Health Services Group, Vocational Rehabilitation, and Facilities Department came together to research ergonomic chairs for Lawrence Berkeley Laboratory (LBL) employees. The group became the "Ergonomics Council $^{*}$ and continued to meet on an ad hoc basis. In 1991, due to an increase in VDT-related injuries, a formalized effort was begun to develop an ergonomics program that reflected LBL's already multidisciplinary approach. Though the initial target group was VDT users, the Council planned to include all types of ergonomic situations. In January 1994, the LBL Ergonomics Committee was established by the EH\&S Division Director. Members from the Ergonomics Council were folded into the committee in addition to other lab-wide representatives. The LBL Ergonomics Committee advises management on LBL ergonomic health problems, possible solutions and preventative strategies, and on policy issues that address legislative and epidemiological trends. The LBL Ergonomics Committee works together with other LBL organizations to address ergonomic issues at LBL. This effort has resulted in the present "systems approach" to ergonomics.

\section{Committee Membership}

The LBL Ergonomics Committee comprises of representatives with a wide range of expertise and disciplines; Administration, Facilities, Health Services, Industrial Hygiene, Materiel Management, Occupational Safety, EH\&S Training, and Vocational Rehabilitation. Committee members meet on a monthly basis.

Mona Bernstein, EH\&S Training: Designed and implemented a VDT training course for LBL employees. She has been involved in the development of the LBL Ergonomics Program, and education of management. An LBL representative on UC's system-wide Ergonomics Task Force; she is a member of the steering, Task Force goals, and research committees. 
Connie Grondona, Health Services Group: Responsible for Health Service's early intervention and medical management of CTDs. She has been involved in the development of the LBL Ergonomics Program, and in education of LBL management. A member of LBL UC furniture bid evaluation team. An LBL representative on the UC Ergonomics Task Force; she is a member of the research committee and the UC-Berkeley policy committee.

Kathleen Handron, Vocational Rehabilitation: Responsible for facilitating ergonomics review as related to return to work, Americans with Disabilities Act, and psycho-social issues.

Bruce King, Industrial Hygiene Group: Assisted in the development of the LBL Ergonomics Policy. Reviewed the DOE Ergonomics Order (draft) and provided recommendations.

Fred Mecum, Facilities: Has a background in installation of work stations at LBL. A member of the LBL UC furniture bid evaluation team.

Kathie Milano, Facilities: Design and monitor projects for the Facilities Department architects and engineers to ensure an ergonomically safe work environment for LBL users. A member of LBL UC furniture bid evaluation team.

Ervette Moore, Occupational Safety: Responsible for oversight of the Ergonomics Program. She has been involved in the development of the LBL Ergonomics program. Conducts ergonomic evaluations. Assisted in the development of the LBL Ergonomics Policy. Serves as Chairperson of the LBL Ergonomics Committee.

Catherine Parrott, Administration Division: Recommends the evaluation of office work stations with poor ergonomic design for the M\&SL Department. Keeps M\&SL abreast of any actions that may require implementation within that department.

Wayne Pearce, Industrial Hygiene Group: Conducts office work station evaluations, especially for injured employees or concerned supervisors. 
Sara Rigler-Udo, EH\&S Training: Conducts ergonomics training for computer users. Developed and teaches a back injury prevention course. Coordinates LBL Ergonomic display areas (e.g., Ergonomics Awareness Week, Ergonomics on Parade). A member of the UC Ergonomics Task Force; she is a member of the communications/resource sharing committee.

Linda Votto, Risk Management: Responsible for coordinating claims management activities related to workers' compensation cases. Analyzes occupational injuries/illnesses that have the potential to become workers' compensation cases.

Dee Wentz, Material Management: She is on the LBL UC furniture bid evaluation team. Purchases furniture, chairs, and accessories, and coordinates VDT display areas. Recently won an LBL safety award for her contributions to the Ergonomics Program.

\section{MAJOR ACCOMPLISHMENTS}

\section{LBL Ergonomics Policy}

The Committee was instrumental in developing the LBL Ergonomics Policy (see Appendix A). The policy addresses office (VDT) and industrial ergonomics. The policy statement also includes the roles and responsibilities for managers/supervisors, and employees. The policy was presented to the Director's Action Committee and approved in April 1994. It provides a broad framework for the Ergonomics Program at LBL.

\section{Health and Safety Manual (PUB 3000)}

A new chapter on Ergonomics, Chapter 17, was added to LBL's Health and Safety Manual (PUB 3000). The Committee provided input on the development of this chapter, which addresses office (VDT) and industrial ergonomics. The LBL Ergonomics Policy is located in this chapter. 


\section{Ergonomic Inspection Assessment}

The LBL Ergonomics Committee stays up-to-date on the types of injuries that are occurring at LBL. Ergonomic evaluations are reviewed periodically to assess ergonomic trends at LBL. A total of 103 VDT ergonomic evaluations were reviewed to assess what problems employees are experiencing with their VDT workstations. Common recommendations made were for employees to purchase an ergonomic chair, institute VDT rest breaks per NIOSH, adjust their keyboard height/angle, and adjust the VDT monitor height/angle. The objects which gave employees the most problems were chairs, desks, and wrist rests/pads. The LBL Ergonomics Committee recommends that employees attend training to learn more about setting up their VDT workstations properly.

Risk management data and LBL injury/illness reports are reviewed to assess trends at LBL on repetitive strain injuries. Trends are analyzed by Division, and for LBL as a whole. The results show that the severity of repetitive strain injuries has decreased substantially since calendar year 1992; 426 lost work-days (LWDs) in 1992, versus 45 LWDs in 1993, and 56 LWDs this year as of $9 / 27 / 94$ (see Appendix B). These results indicate that the LBL Ergonomics Committee member's efforts to enhance employee awareness of ergonomics are having a positive impact on reducing RSI severity and costs.

\section{Ergonomic Legislation}

Several ergonomic regulations and standards are in development to address ergonomics at the workplace. At the local level, Cal-OSHA has proposed an Ergonomic Regulation, Article 106, Section 5110 "Prevention of Cumulative Trauma Disorders (Ergonomics)". Several Committee members participated in the local public hearing on February 24, 1994, in San Francisco. Cal-OSHA's target date to have its Ergonomic Regulation take effect is January 1, 1995 . At the national level, Committee members provided input to DOE's proposed Ergonomic Order, and the $\mathrm{NIOSH} / \mathrm{OSHA}$ proposed Ergonomic Standard. OSHA is in the final stages of producing their proposed Ergonomic Standard. It should be released sometime this fall. The DOE initiative has been withdrawn since DOE is supporting NIOSH/OSHA efforts. 


\section{Ergonomic Training}

Several members of the Committee are involved with developing ergonomic courses and providing training. This past fiscal year, a new course titled "Back Injury Prevention" was developed to target employees who are at risk for sustaining a back injury. The Committee provided input on the development of course content. The course is taught by EH\&S Training as two modules. Eighteen classes (36 modules) were taught and 234 employees were trained. Approximately $90 \%$ of Maintenance \& Operation employees were trained. Another ergonomics course is offered on a continuous basis, Ergonomics for Computer Users. Seven classes were taught in FY 94 and 58 employees were trained.

\section{Ergonomics Awareness Week}

The first Ergonomics Awareness Week was held March 7-11, 1994 (see Appendix C). An ergonomic display was set up including brochures, alternative keyboards, posters, furniture, accessories, and videos. This event attracted approximately $400 \mathrm{LBL}$ employees and guests. Many of the employees who stopped at the display table had not visited LBL's Office Ergonomics Lab, and were pleased to find all the equipment at the cafeteria. A total of 145 employees signed up for additional information. Of these, 6 showed interest in training, 9 were interested in borrowing videos, 61 were interested in ergonomic furniture and accessories, and 40 were interested in the chair loaner program. One week after the Ergonomics Awareness Week, attendance at the Office Ergonomics Lab was higher than usual. The next Ergonomics Awareness Week is scheduled for November 14-18, 1994, at the cafeteria during the lunch period (see Appendix C).

\section{Ergonomics On Parade}

The Energy and Environment Division sponsored Ergonomics on Parade which was held in Building 90, September 28-30, 1994. An Ergonomic Committee member coordinated the set up of the VDT display area, and 
their ergonomic products. Approximately 70 employees attended this event. The exhibition included state-of-the-art furniture, software, and keyboards. Employees had the opportunity to evaluate 3 ergonomic software programs: Lifeguard, Ergoknowledge and Dragon Dictate. In addition, several alternative keyboards were available: Kinesis, Comfort, Ergologic, and Marquardt.

\section{OTHER ACCOMPLISHMENTS}

Although the LBL Ergonomics Committee was established in FY 94, the adhoc Ergonomics Council was responsible for the development of the following accomplishments that should be acknowledged:

\section{LBL Office Ergonomics Lab}

The Office Ergonomics Lab is located in trailer 7B. This lab is updated with state-of-the art ergonomic furniture and accessories. An ergonomically correct VDT workstation display is set up, and educational material is available. See Appendix $D$ for more information.

\section{LBL Ergonomic Furniture Policy}

A new Furniture Policy which encompasses ergonomic considerations for furniture and accessories as part of the purchasing process, was developed and approved during FY 93. As a result, ergonomic furniture and accessories have been added to LBL stores, and purchases have increased.

\section{LBL Chair Loaner Program}

Employees are able to borrow samples of ergonomic chairs temporarily to determine the suitability and comfort of a chair for their individual needs. 


\section{PLANNING FOR THE FUTURE}

Through the efforts of LBL's Ergonomics Committee, much has been accomplished during FY 94. The Committee will continue to work diligently to identify areas that need ergonomic improvements, and initiate action to correct ergonomic deficiencies in a cost-effective manner.

\section{Opportunities for Improvement at LBL}

Currently, many LBL managers, supervisors and employees are aware of ergonomics, but not all. During FY 95, the Committee will continue to interact with EH\&S Training to develop more ergonomic courses. EH\&S Training is in the process of developing a program for managers and supervisors who supervise employees that fall into a high risk category for potentially developing a CTD. Managers and supervisors have responsibilities for providing an ergonomically-safe workplace. The Committee will also continue to initiate activities to enhance the awareness of ergonomics at LBL, and focus on ways to attract more LBL employees to these activities.

\section{Ergonomic Legislation}

The Committee will continue to monitor proposed federal and state ergonomic legislation and standards, and analyze their potential impact at LBL. We will continue to advise management on the status and potential impact of these ergonomic initiatives. The Committee will continue to provide comments on proposed ergonomic legislation and standards, when requested or appropriate.

\section{Ergonomic Furniture and Accessories}

The Committee will continue to stay up-to-date on state-of-the-art ergonomic furniture and accessories. Periodically, the Committee invites representatives for ergonomic furniture, accessories and keyboard manufacturers to teach us about these new products. In some cases, we have the opportunity to borrow products for evaluation purposes. 
APPENDIX A 


\section{LBL'S ERGONOMICS POLICY}

Lawrence Berkeley Laboratory shall maintain and implement an Ergonomics Program that identifies, prevents, and controls ergonomic hazards in accordance with all applicable rules and regulations. The Ergonomics Program shall consist of health and risk factor surveillance, work site evaluations and improvement, medical management, training, and program review and evaluation. Strategies for reducing risk factors shall focus on engineering controls when feasible, and/or administrative controls. The purpose of the Ergonomics Program is to minimize employee exposure to ergonomic hazards that lead to cumulative trauma disorders (CTDs), and related injuries and illnesses. Cumulative Trauma Disorders are disorders of the muscles, tendons, and/or nerves that develop from or are aggravated by repeated exertions or movements of the body. This program will have an impact on employees who may be exposed to ergonomic risks, such as video display terminal (VDT) operators, material handlers, and hand tool operators. All division directors, department heads, group leaders, supervisors, and individuals have responsibilities to help ensure a safe and healthful work environment. Therefore, commitment and cooperation from all employees at all levels is required to implement this policy.

- The Director's Action Committee (DAC) reviewed this policy and gave approval on April 13, 1994. 


\section{APPENDIX B}




\section{Worker Compensation Numbers and Costs of VDT Injuries FY 1992, 1993 \& 1994}

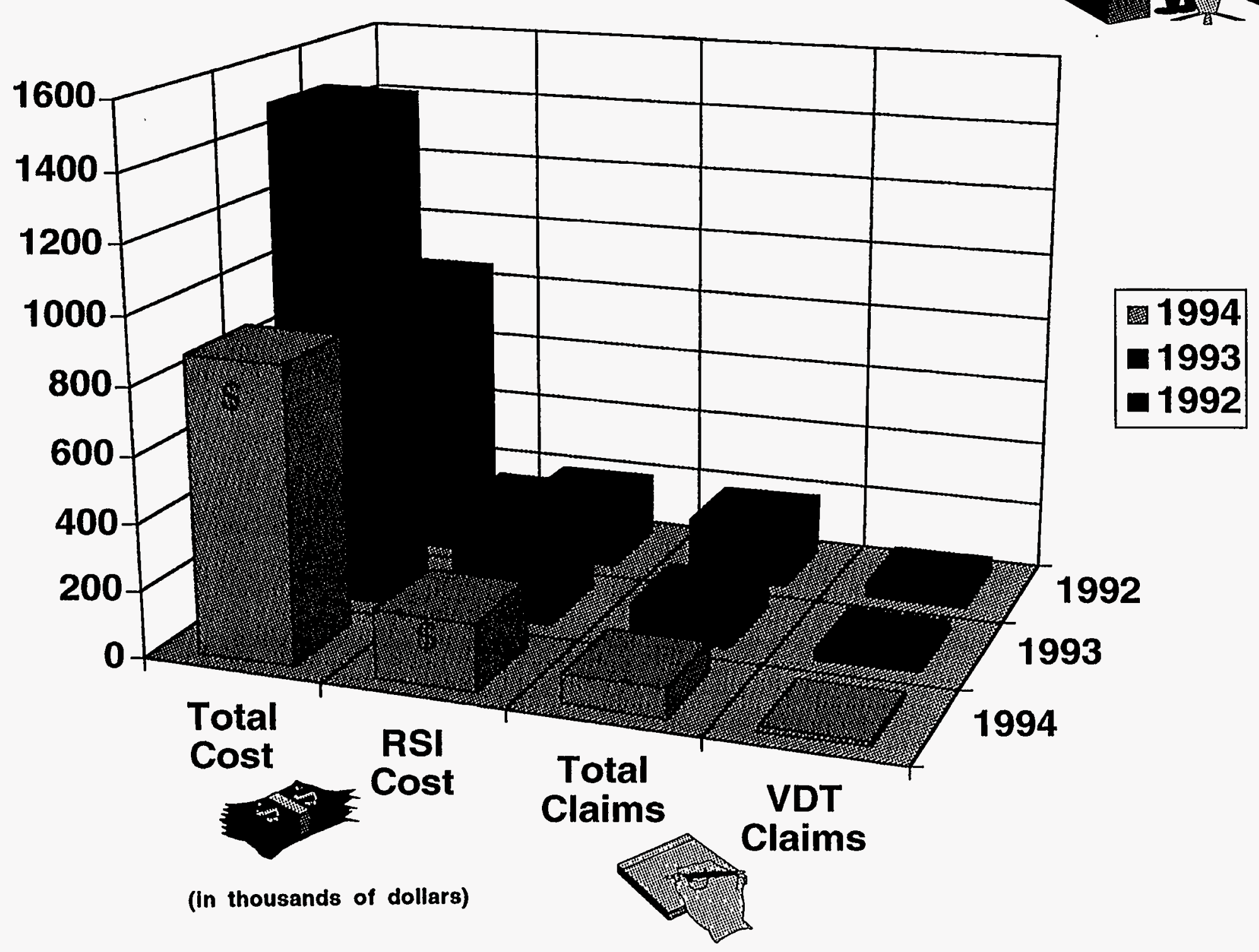




\section{LBL Injury/llIness Reporting 1994, Calendar YTD}

- There were 39 illnesses, of which 26 were repetitive strains (18 VDT related)

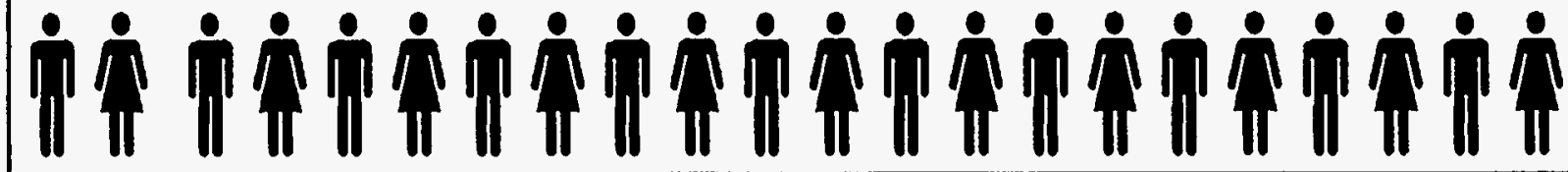

4 LWD

3 VDT Related

宜官 || ता ||
22 had no lost work-days

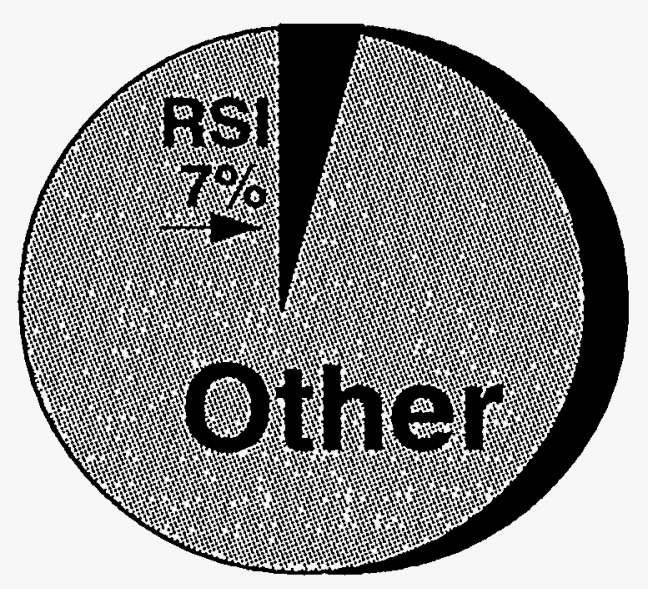

56 lost workdays is $7 \%$ of LBL's total of 796 lost work days YTD
4 had 56 lost workdays (14 avg. perl RSI case) 


\section{LBL Injury/lllness Reporting, 1993}

- There were 44 illnesses, of which

\begin{tabular}{|c|c|c|}
\hline & \multicolumn{2}{|c|}{38 were repetitive strains (34 VDT related) } \\
\hline & 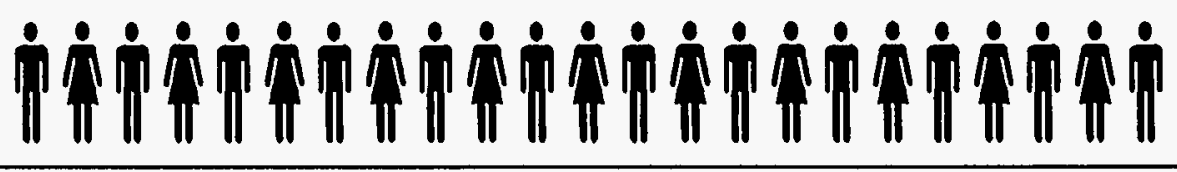 & 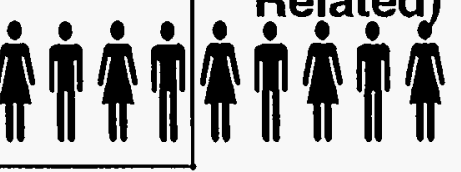 \\
\hline & 33 had no lost work-days & 5 had 45 \\
\hline & $\begin{array}{l}45 \text { lost work- } \\
\text { days is } 2.2 \% \\
\text { of LBL's total } \\
\text { of } 2039 \text { lost } \\
\text { work days }\end{array}$ & $\begin{array}{l}\text { work- } \\
\text { days ( } 9 \\
\text { avg. perl } \\
\text { RSI } \\
\text { case) }\end{array}$ \\
\hline
\end{tabular}




\section{LBL Injury/llIness Reporting, 1992}

- There were 23 illnesses, of which
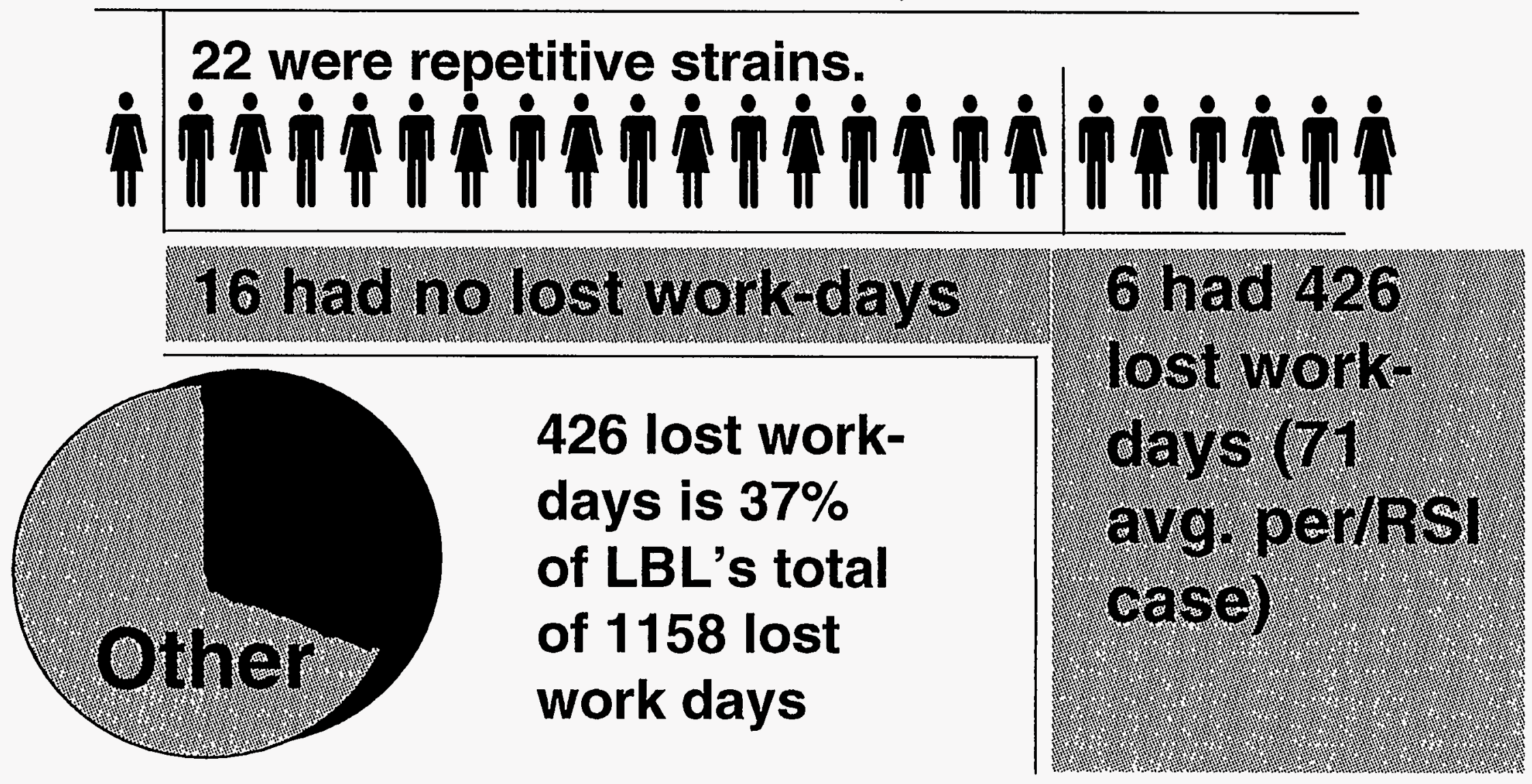
APPENDIX C 


\section{Ergonomics Awareness}

\section{March 7-11, 1994}

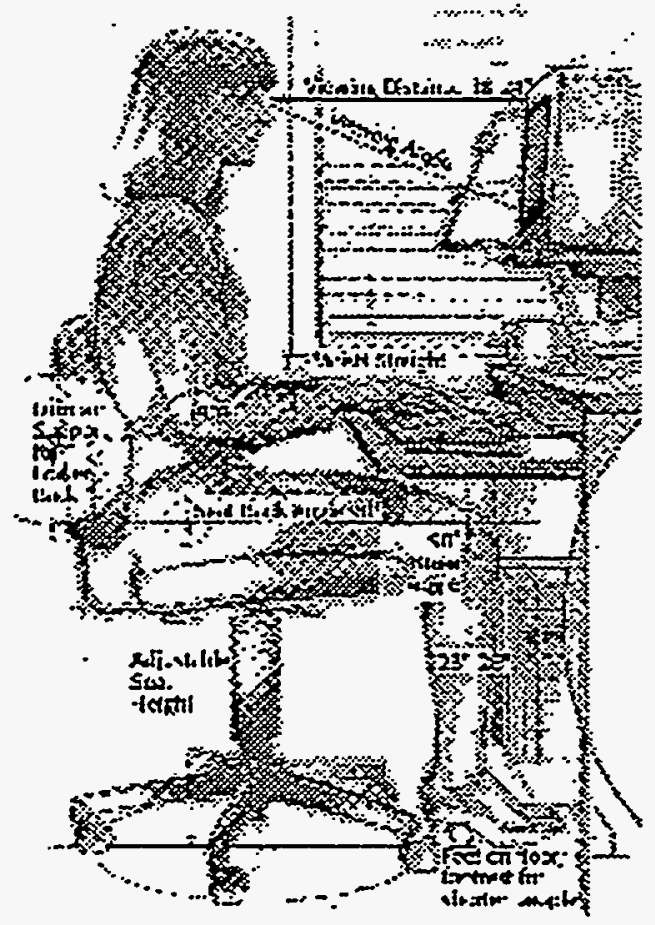

LBL Cafeteria

Monday-Friday

11:30 am-1:00 pm

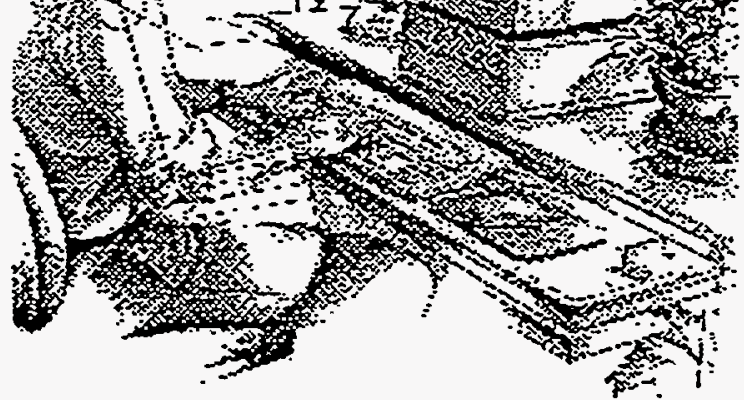

EH\&S, Facilities \& Inventory Management will be present at information tables to answer questions about ergonomics.

Visitors can try out ergonomic furniture and accessories and/or sign up to borrow educational materials or take classes. Each day, an ergonomic accessory will be given away to visitors who come to the display area.

\section{You may be the lucky one!}

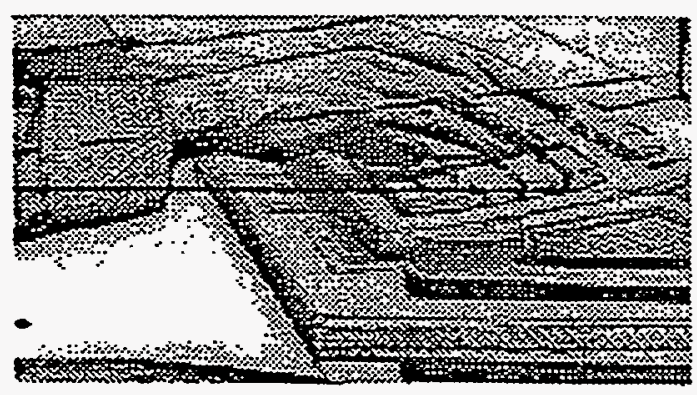




\section{Ergonomics Awareness}

November 14-18, 1994
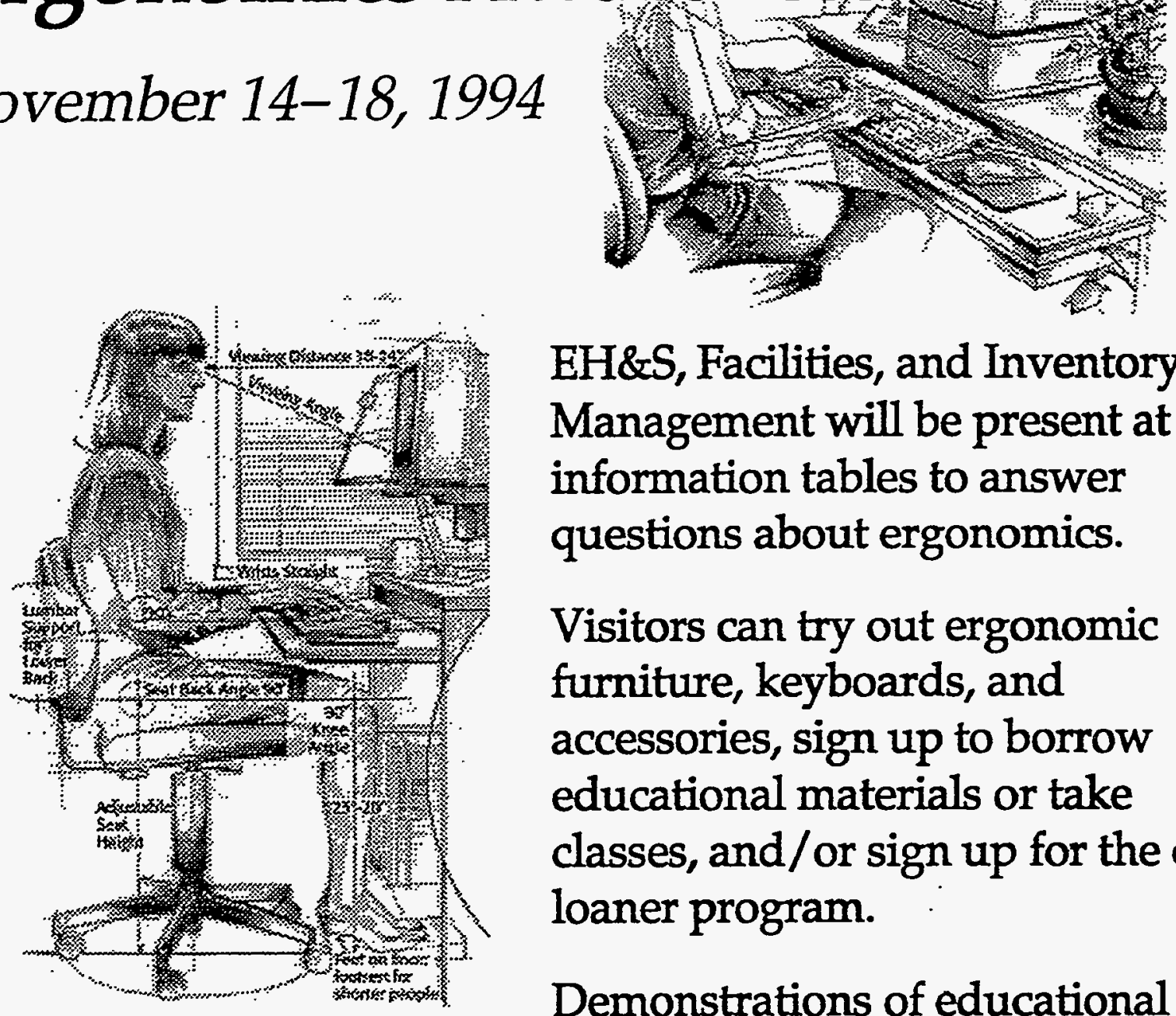

EH\&S, Facilities, and Inventory Management will be present at information tables to answer questions about ergonomics.

Visitors can try out ergonomic furniture, keyboards, and accessories, sign up to borrow educational materials or take classes, and/or sign up for the chair loaner program.

Demonstrations of educational ergonomic software and voice input

LBL Cafeteria programs will also be conducted.

\section{Monday-Friday \\ 11:30 am-1 pm}

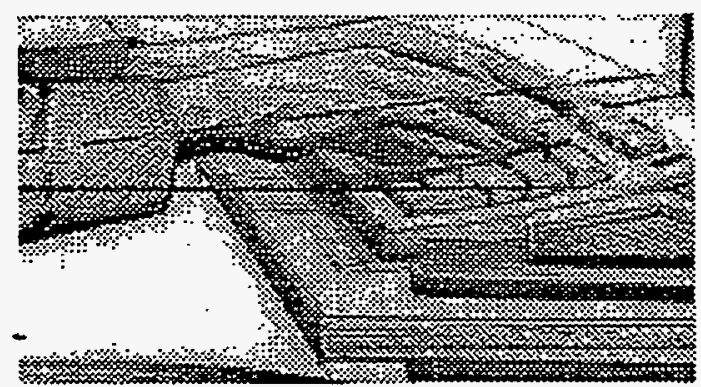

Contact Sara Rigler-Udo at extension 6614 for more information. Sponsored by the LBL Ergonomics Committee. 
APPENDIX D 

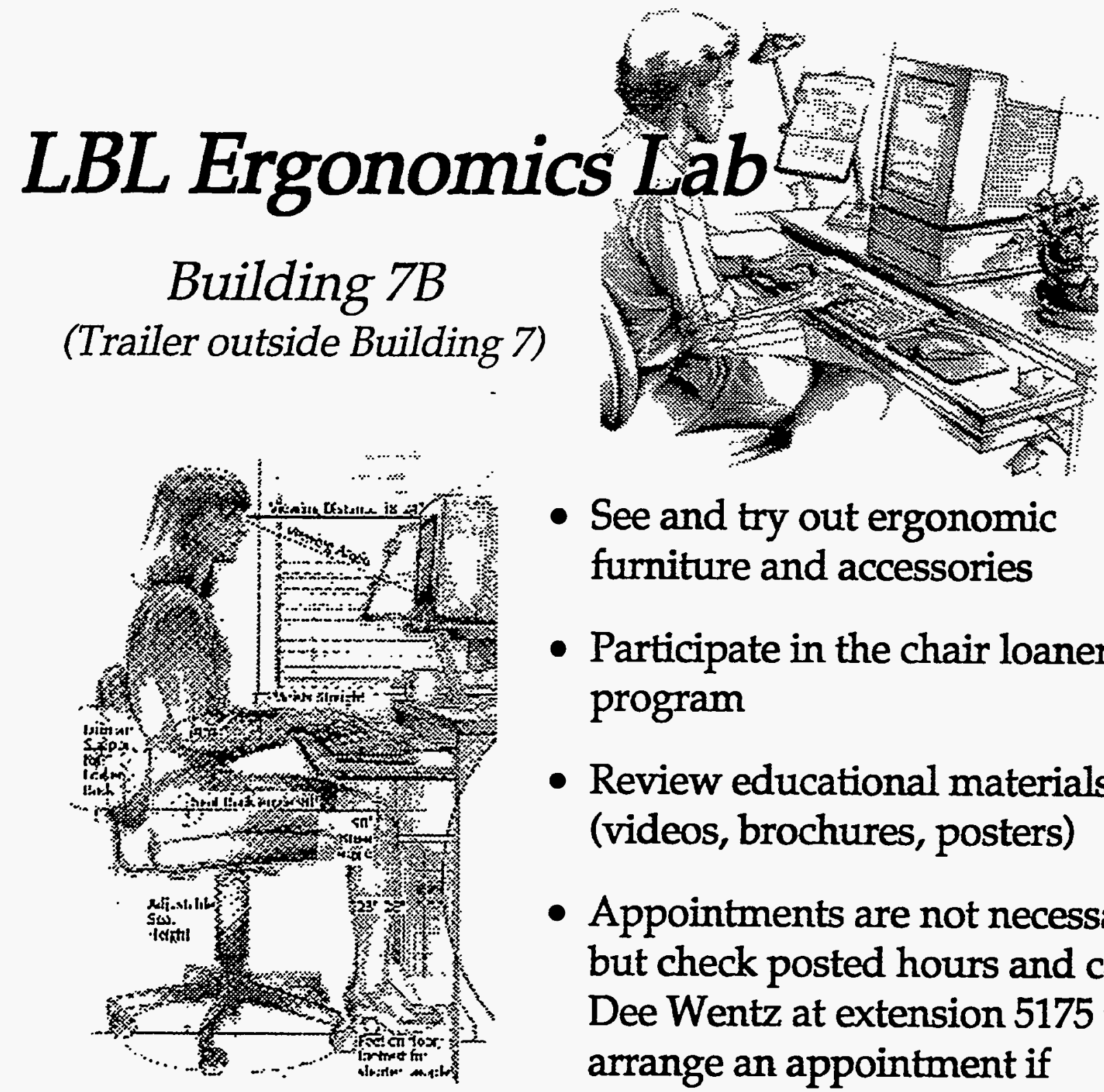

- See and try out ergonomic furniture and accessories

- Participate in the chair loaner program

- Review educational materials (videos, brochures, posters)

- Appointments are not necessary, but check posted hours and call Dee Wentz at extension 5175 to arrange an appointment if desired.

Open Monday through Friday

$$
\begin{gathered}
\text { 6:30 am-11 am; } \\
1 \mathrm{pm}-2: 30 \mathrm{pm}
\end{gathered}
$$

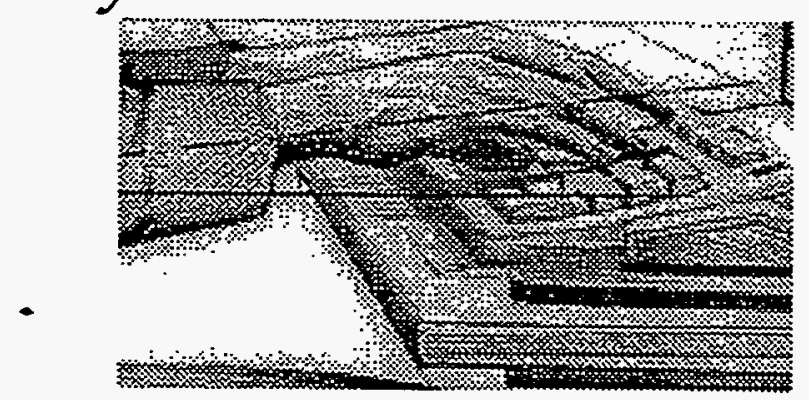

For more information call Sara Rigler-Udo, extension 6614, or Dee Wentz, extension 5175. 


\section{APPENDIX E}


LAWRENCE BERKELEY LABORATORY

Environment, Health and Safety Division

Bldg: 90 Room: 2102 Ext: 6135

October 3, 1994

OS-95: 001

\section{MEMORANDUM}

TO: $\quad$ Paul Johnson

FROM: $\quad$ Ervette Moore

Occupational Safety Group

SUBJECT: FY95 and FY96 Budget Proposals for the LBL Ergonomic Committee

For fiscal year 1995 (FY 95), the LBL Ergonomic Committee is requesting $\$ 5,940.00$.

Listed below is an itemization of how the funds will be spent:

1. A computer (Mac or IBM) to demonstrate ergonomic software $\$ 2,500.00$ packages with the following specifications;

$4 \mathrm{MB}$ RAM and $160 \mathrm{MB}$ Hard drive, built-in CD Rom

monitor - color with minimum 250 colors, $14^{\prime \prime}$ screen

2. A phone with voice recording for the ergonomics lab $\$ 1,040.00$ installation - $\$ 500$ monthly service fee - $\$ 45$

3. Ergonomic lab upgrades

(e.g., alternative keyboards, tables, chairs, etc.)

$\$ 2,000.00$

4. LBL Ergonomic Committee Annual Report

TID charges for printing (black \& white), binding, and distribution only

5. Ergonomic software packages for demonstration on the computers

100.00 in the ergonomics lab. Note: Software packages for lab-wide use cost approximately $\$ 20$ to $\$ 40$ per computer that these packages are installed on.

TOTAL for FY 95

$\$ 5,940.00$

Note: The LBL ergonomic committee needs approximately 225 square feet of space for permanent relocation of the Ergonomics lab. There are approximately 27 visits/month to the ergonomics lab by LBL employees. 


\section{Budget Proposal for FY 96}

For fiscal year 1996 (FY 96), the LBL Ergonomic Committee is requesting $\$ 3,900.00$. Listed below is an itemization of how the funds will be spent:

1. Ergonomic lab upgrades (annually)

$\$ 3,000.00$

(e.g., alternative keyboards, tables, chairs, software, etc.)

2. A phone with voice recording for the ergonomics lab

600.00 monthly service fee $-\$ 50$ estimate

3. LBL Ergonomic Committee Annual Report

300.00

TID charges for printing (black \& white), binding, and distribution only

EM

cc:

file: Ergonomics 